\title{
Ensayo sobre la carga de la prueba del incumplimiento contractual en la ley sobre Protección de los derechos de los Consumidores
}

\author{
Andrés Erbetta Mattig*
}

\begin{abstract}
RESUMEN
La Ley $N^{\circ} 19.496$ no contiene una norma que distribuya la carga de la prueba, no obstante calificar como abusivas -en los contratos de adhesión - las cláusulas que la inviertan en perjuicio del consumidor. En este ensayo se formulará una propuesta específica en relación con el peso probatorio del incumplimiento contractual, en materia de garantía legal de productos y servicios, acorde con los principios que inspiran la legislación del consumo.
\end{abstract}

Carga de la prueba - incumplimiento contractual - protección de los consumidores

\section{Essay of burden of proof for breach of contract in the law on the protection of consumer rights}

\begin{abstract}
Law $N^{\circ} 19,496$ does not contain a regulation that distributes the burden of the proof, in spite of qualifying as abusive -in the adhesion contracts - the clauses that invert it in detriment of the consumer. In this essay a specific proposal regarding the burden of proof of the breach of contract will be formulated, in the subject of legal warranty of products and services, in accordance with the principles which inspire the consumer legislation.
\end{abstract}

Burden of proof - breach of contract - consumer protection

* Licenciado en Ciencias Jurídicas, Universidad Diego Portales. Magíster en Derecho Privado, Universidad de los Andes. Correo electrónico: aerbettamattig@gmail.com

Artículo recibido el 14 de noviembre de 2016 y aceptado para su publicación en este número el 23 de julio de 2018. 


\section{INTRODUCCIÓN}

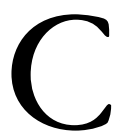
omo es sabido, la Ley $\mathrm{N}^{\circ}$ 19.496, sobre Protección de los Derechos de los Consumidores $^{1}$ no cuenta con una regulación completa del régimen probatorio de los procesos a que la aplicación de ella da lugar ${ }^{2}$, lo que incluye lo referido a la carga de la prueba. No obstante, al elaborar la "lista negra" de cláusulas nulas en el contrato de adhesión, el art. 16 d) dispone que no producirán efecto aquellas que "inviertan la carga de la prueba en perjuicio del consumidor". En este ensayo abordaremos este tópico de la LPC, en particular respecto de aquellas contravenciones que supongan un incumplimiento contractual sin infracción a las disposiciones de dicha ley ${ }^{3-4}$, esto es, las que se refieren al ejercicio de la garantía legal en materia de productos (arts. 19-21) y servicios (art. 41)

\section{LA CARGA DE LA PRUEBA EN EL MARCO DE LA LPC}

Como advertimos, el art. 16 d) sanciona con nulidad las cláusulas de un contrato de adhesión que invierten el peso de la prueba en perjuicio del consumidor. Pero más allá

${ }^{1}$ En adelante LPC. Si no se indica algo distinto, todos los artículos citados corresponden a dicho cuerpo legal.

${ }^{2}$ Por todos, Cortez, G., El nuevo procedimiento regulado en la Ley $N^{\circ} 19.496$ sobre Protección de los Derechos de los Consumidores, Edit. LexisNexis, Santiago, 2004, pp. 57-58.

${ }^{3}$ Para efectos de este trabajo, recurrimos a la clasificación propuesta por Guerrero, J.L., "La distinción entre contravención infraccional e incumplimiento contractual o contravención civil en materia de protección de derechos del consumidor", en Guzmán, A. (editor científico), Colección de estudios de derecho civil en homenaje a la profesora Inés Pardo de Carvallo, Ediciones Universitarias de Valparaíso, Valparaíso, 2008, pp. 442-453, quien distingue tres tipos de acciones en el marco de la LPC: a. Infracción sin incumplimiento contractual; b. Incumplimiento contractual sin infracción, y c. Infracción e incumplimiento contractual (situaciones mixtas).

${ }^{4}$ No obstante el carácter marcadamente sancionatorio de la LPC, para efectuar este análisis tenemos en cuenta lo dispuesto en el art. $50 \mathrm{~B}$, que permite deducir una acción civil ("los procedimientos previstos en esta ley podrán iniciarse por demanda") sin acompañarla de una de tipo infraccional. Si bien los tribunales han sido reacios a acoger la independencia de la acción civil, algunos fallos han distinguido con claridad la distinta naturaleza de las acciones que la ley consagra. En este sentido pueden verse "Arias Madariaga con Sodimac S.A.", Corte de Apelaciones de Concepción, 24 de diciembre de 2007, Rol 174-2005, y "Sernac con Cencosud", Corte Suprema, 24 de abril de 2013, Rol 12.355-2011.

${ }^{5}$ Es factible señalar que en relación con los procesos originados por presunta infracción al art. 23 LPC, LORENZINI, J., "La carga dinámica de la prueba en materias de consumo: un desafío pendiente para asegurar la igualdad procesal del consumidor y proveedor", en TAPIA, M., GaticA, M.P. y Verdugo, J., (coordinadores), Estudios de derecho civil en homenaje a Gonzalo Figueroa Yã̃ez, Edit. LegalPublishing, Santiago, 2014, pp. 387 y s., ha propuesto de lege ferenda la positivización del sistema de cargas dinámicas de la prueba, para acudir en auxilio del consumidor en aquellos supuestos en que la aportación de prueba resulte imposible.

${ }^{6}$ No podemos dejar pasar la oportunidad de criticar la sistemática de la LPC, que construye dos sistemas de remedios típicos - para productos y servicios, respectivamente-, en desmedro de un sistema unitario y articulado para ambos. Una crítica similar puede verse en BARAONA, J., "La regulación contenida en la Ley N $\mathrm{N}^{\circ} 19.496$ sobre Protección de los Derechos de los Consumidores y las reglas del Código Civil y Comercial sobre contratos: un marco comparativo", en Revista Chilena de Derecho, v. 41, No 2, 2014, p. 393. 
de que en la práctica será difícil encontrar supuestos en que abiertamente se produzca dicha inversión -la evidencia demuestra que lo usual es que se limite la forma en que se pueden probar determinados hechos, antes que afectar la carga misma ${ }^{7}$-, la disposición es interesante porque no prejuzga respecto de cuál debe ser el régimen de la carga de la prueba del incumplimiento contractual en el marco de la LPC. La solución que ha dado la doctrina -y que compartimos- es el recurso al derecho común, particularmente al art. 1698 inc. $1^{\circ}$ del Código Civil ${ }^{8-9}$. En este sentido, podemos citar a Aimone Gibson ${ }^{10}$ y el importante trabajo de Tapia y Valdivia acerca del contrato de adhesión ${ }^{11}$.

Resuelto lo anterior, sin embargo, el aspecto más problemático parece ser el tránsito del CC a la LPC. Al respecto, la lectura que formula la doctrina más autorizada sobre el art. $16 \mathrm{~d}$ ), conecta la cuestión de la prueba con la indemnización de perjuicios y el fundamento subjetivo que tradicionalmente se le asigna en el derecho común ${ }^{12}$. En esta tesitura se encuentran Tapia y Valdivia, quienes sostienen que "el carácter abusivo de esta cláusula radica en el estado de indefensión en que deja al adherente, pues de aceptarse la inversión, si no consigue acreditar que el incumplimiento del contrato es

${ }^{7}$ En este sentido Fuentes, C., “Comentario al artículo 16 D)”, en De la Maza, I., y Pizarro, C. (directores) y BARrientos, F. (coordinadora), La protección de los derechos de los consumidores, Edit. LegalPublishing, Santiago, 2013, p. 323, quien sostiene que estas cláusulas, en verdad, constituyen verdaderas limitaciones de responsabilidad. También, véase García, M., Cláusulas limitativas de la responsabilidad contractual, Edit. Tecnos, Madrid, 1965, pp. 178-181.

${ }^{8}$ En adelante CC.

9 Entendemos que la carga de la prueba constituye un aspecto propio del derecho sustantivo, sin perjuicio de las aportaciones del derecho procesal. En este sentido, seguimos a Corral, H., "Sobre la carga de la prueba en el proyecto de Código Procesal Civil”, en Aguirrezabal, M. (editor), Justicia Civil: perspectivas para una reforma en la legislación chilena, Cuadernos de Extensión Jurídica $\mathrm{N}^{\circ} 23$, Universidad de los Andes, Santiago, 2012, pp. 107-108, quien, para concluir de este modo, sostiene que la carga de la prueba orienta al juez respecto del contenido de la sentencia y no por la forma de emitirla. También pueden consultarse Jordano, F., La responsabilidad contractual, Civitas, Madrid, 1987, p. 248; RosenberG, L., La carga de la prueba, (trad.) Krotoschin, E., B de F, Buenos Aires, 2002, pp. 102-103, y Morales Moreno, A.M., "Comentario al artículo 35", en Díez-PiCAzo, L. (coord.), La compraventa internacional de mercaderías. Comentario de la Convención de Viena, Thomson Civitas, Cizur Menor, 2006, p. 310.

${ }^{10}$ Aimone, E., Derecho de protección al consumidor, Edit. Jurídica Conosur, Santiago, 1998, p. 77: “En conformidad al tan conocido art. 1698 del Código Civil, 'incumbe probar las obligaciones o su extinción al que alega aquellos o esta'. En consecuencia, no puede, por ejemplo, un contrato de adhesión en materia telefónica, en el caso de llamadas cobradas por la empresa y cuestionadas por el consumidor, pretender que este pruebe que no hizo la llamada. Lo que procede es que la telefónica pruebe que la llamada fue hecha”. El mismo ejemplo es citado en SANDOval, R., Derecho del consumidor. Protección del consumidor en la Ley $N^{\circ} 19.496$, de 1997, modificada por la Ley $N^{\circ} 19.955$, de 14 de julio de 2004, y en la legislación comparada, Edit. Jurídica de Chile, Santiago, 2004, p. 90.

11 Tapia, M. y Valdivia, J.M., Contrato por adhesión. Ley $N^{o}$ 19.496, Edit. Jurídica de Chile, Santiago, 2002, pp. 118-122.

${ }^{12}$ En este sentido, Claro Solar, L., Explicaciones de derecho civil chileno y comparado. De las obligaciones, t. XI, Edit. Nascimento, Santiago, 1937, pp. 497-498; Alessandri, A., Teoría general de las obligaciones, Edit. Jurídica Ediar Conosur, Santiago, 1988, p. 80; y BARros, E., "La diferencia entre estar obligado y ser responsable en el derecho de los contratos”. En Corral, H. y Rodríguez, M.S. (coord.), Estudios de Derecho Civil II, Edit. LexisNexis, Santiago, 2007, p. 724. 
imputable a la culpa del empresario, los perjuicios que sufra no serán indemnizados" 13 . No obstante, apoyándose en la clasificación bimembre obligaciones de medios y de resultado, entienden que solo en las segundas el acreedor se beneficiaría de una presunción de culpa, ya que respecto de las primeras tocará a este probar la negligencia y, por tanto, el incumplimiento ${ }^{14}$. De esta forma, concluyen, el alcance de la LPC en esta materia es limitado, por cuanto únicamente confirma las reglas generales que rigen la distribución probatoria, pero no mejora la posición del consumidor ${ }^{15}$.

\section{LA CARGA DE LA PRUEBA DEL INCUMPLIMIENTO CONTRACTUAL EN EL CC}

Lo expuesto en el apartado precedente nos obliga a tomar una postura respecto del régimen de la carga de la prueba del incumplimiento en el CC, como paso previo a su importación a la LPC. Para efectuar este traspaso partimos de ciertas premisas que, por su extensión, solo enunciaremos en este lugar. Una primera consideración es que el resarcimiento de los daños es solo una de las acciones que integran la variedad de acciones a disposición del acreedor. Con mayor propiedad, entonces, se habla de un sistema de remedios articulado sobre una noción unitaria de incumplimiento contractual, que constituye el supuesto básico ${ }^{16}$. Teniendo presente lo anterior, es posible la construcción de cargas probatorias del incumplimiento que, aun reconociendo la particular especificidad de cada remedio, sean transversales a todos los supuestos.

La segunda es que para los fines unificadores que modernamente se le atribuyen, el incumplimiento es objetivo -no precisa de culpa o dolo-, y es "el resultado de la simple constatación de la falta de coincidencia entre el dato ideal (lo prometido) y el dato real (lo ejecutado por el deudor), y la consiguiente insatisfacción del interés del acreedor" ${ }^{17}$. Esta noción se integra al supuesto particular de cada uno de los remedios ${ }^{18-19}$.

13 Tapia, M. y Valdivia, J.M., op. cit., $\mathrm{N}^{\mathrm{o}} 11$, p. 118.

14 Tapia, M. y Valdivia, J.M., op. cit., $\mathrm{N}^{0} 11$, p. 119.

15 TAPiA, M. y Valdivia, J.M., op. cit., $\mathrm{N}^{\mathrm{o}} 11$, p. 121.

${ }^{16}$ Morales Moreno, A.M., "Claves de la modernización del derecho de contratos”, en De la Maza, I., Morales Moreno, A.M. y Vidal, A., Estudios de derecho de contratos. Formación, cumplimiento e incumplimiento, Edit. Thomson Reuters, Santiago, 2014, pp. 94-95.

17 VIDAL, Á., "Responsabilidad civil por incumplimiento de obligaciones con objeto fungible. Una relectura de las disposiciones del Código Civil sobre incumplimiento", en DE LA MAZA, I., Morales Moreno, A.M. y Vidal, A., Estudios de derecho de contratos. Formación, cumplimiento e incumplimiento, Edit. Thomson Reuters, Santiago, 2014, p. 149. En términos similares, Corral, H., Contratos y daños por incumplimiento, Edit. LegalPublishing, Santiago, 2010, p. 154

${ }^{18}$ Morales Moreno, A.M., op. cit., $\mathrm{N}^{\circ} 16$, p. 95.

${ }^{19}$ Así por ejemplo, para VIDAL, Á., op. cit., No 17, pp. 160, 176-178, habría que agregar el factor de imputación subjetivo (culpa o dolo), aunque solo en la indemnización. PeÑaIlillo, D., "Responsabilidad contractual objetiva”, en Pizarro, C. (coord.), Estudios de Derecho Civil IV, Edit. LegalPublishing, Santiago, 2009 , p. 338, en cambio, sostiene que la culpa no constituye un presupuesto de la indemnización, lo que se desprende, entre otras disposiciones, del art. 1556 CC. 
Finalmente, es posible diferenciar entre la prestación en sí -cuya configuración será eminentemente objetiva- y los daños consecuenciales que exceden de su valor, distingo que permitirá localizar las exigencias de casualidad y previsibilidad ${ }^{20}$ en forma exclusiva en la indemnización stricto sensu. Esta categorización la hacemos extensible al subrogado real, cuando la prestación se ha hecho imposible o inidónea para satisfacer el interés tutelado por el contrato, y a los daños por sobre el equivalente (aestimatio rei e id quod interest, respectivamente $)^{21}$. De este modo, si la prestación no es susceptible de cumplirse in natura, el equivalente compartirá su naturaleza objetiva ${ }^{22}$. En cambio, los daños por sobre el valor de la prestación reclamarán la concurrencia de los requisitos ya señalados ${ }^{23}$. La importancia de este distingo es que permite delinear con claridad dos planos de cargas probatorias por incumplimiento, al ser diferente el objeto en cada uno ${ }^{24}$.

En el primero el objeto de la prueba lo constituye la materialidad de la prestación (que denominamos "primer nivel de responsabilidad" o "fase material"), y en el segundo los perjuicios consecuenciales ("segundo nivel de responsabilidad" o "juicio de imputación o responsabilidad") ${ }^{25}$. La finalidad probatoria de la fase material será establecer si el deudor satisfizo el interés del acreedor, mediante hechos (actos u omisiones) objetivamente idóneos para dicho fin. En el juicio de responsabilidad, en cambio, determinar si los daños ocasionados a partir de la inejecución deben ser resarcidos por el deudor. En este, el acreedor deberá probar, por regla general, la existencia de los perjuicios ${ }^{26}$, la causalidad con el incumplimiento y si la extensión de estos cuadra con la distribución de riesgos dibujada por la regla contractual ${ }^{27}$.

La inejecución propiamente tal, entonces, corresponde al primer nivel de responsabilidad y viene a ser la manifestación empírica del interés insatisfecho. Por lo mismo, puede revelarse de diversas formas, según la particular economía del contrato. Esto

${ }^{20}$ Más la exigencia de imputación subjetiva (culpa o dolo), si se acepta como presupuesto de la responsabilidad contractual.

${ }^{21}$ En este sentido, Baraona, J., "Responsabilidad contractual y factores de imputación de daños: apuntes para una relectura en clave objetiva”, en Revista Chilena de Derecho, v. 24, No 1, 1997, pp. 156-162, y Contardo, J.I., Indemnización y resolución por incumplimiento, Edit. Thomson Reuters, Santiago, 2015, pp. 47-53. También véase BARros, E., op. cit., $\mathrm{N}^{\circ} 12$, pp. 721 y s.

22 Peñallillo, D., op. cit., $\mathrm{N}^{\circ} 19$, p. 335.

${ }^{23}$ Ver supra nota 19.

${ }^{24}$ En particular, respecto de la carga de la prueba de la imposibilidad, debemos hacer una precisión. Si el acreedor acciona instando por el cumplimiento en naturaleza y el deudor se excepciona alegando que se hizo imposible, corresponde a este probar que ello ocurrió por una causa extraña. En este sentido, BARros, E., op. cit., $\mathrm{N}^{\circ} 12$, p. 738. Pero si el acreedor demanda directamente el equivalente pecuniario, recae sobre él la prueba de la imposibilidad. Así lo entiende Von Tuhr, A., Tratado de las obligaciones, (trad.) Roces, W., Edit. Comares, Granada, 2007, p. 330.

${ }^{25}$ Tomamos el distingo que, entre otros, han adoptado autores como BARros, E., op. cit., N $\mathrm{N}^{\mathrm{o}} 12$, pp. $721 \mathrm{~s}$.

${ }^{26}$ Una excepción a esta regla la constituye la indemnización de perjuicios moratorios cuando la obligación es de pagar una cantidad de dinero, puesto que en ella "el acreedor no tiene necesidad de justificar perjuicios cuando solo cobra intereses; basta el hecho del retardo" (art. 1559 regla 2 ${ }^{\mathrm{a}} \mathrm{CC}$ ).

${ }^{27}$ Reiteramos, a lo anterior la mayoría de la doctrina agrega el factor de imputación subjetivo (culpa o dolo). Ver supra nota 19. 
explica que las cargas probatorias no operen siempre del mismo modo. De acuerdo con el principio cardinal del art. 1698 inc. $1^{\circ} \mathrm{CC}$, en una buena parte de los supuestos corresponderá al acreedor acreditar la relación obligatoria que se estima infringida y nada más alegar el incumplimiento para trasladar el peso de la prueba del cumplimiento al deudor $^{28}$, quien soportará las consecuencias adversas de la inobservancia de dicha carga. Este régimen se aplicará cuando el incumplimiento sea total, parcial e incluso para el cumplimiento retardado de obligaciones de dar y de hacer ${ }^{29}$. En todos estos casos, el deudor deberá rendir la prueba del cumplimiento, identificado, como dijimos, con la realización del interés del acreedor acorde a la particular regla contractual.

Ello no importa enjuiciar los esfuerzos desplegados para cumplir lo acordado, porque incluso en las obligaciones amañadas por un hacer diligente, la inejecución de lo pactado no significa otra cosa que la constatación del hecho objetivo del incumplimiento ${ }^{30}$. Por lo mismo, en estas el deudor también deberá proveer la prueba de los hechos materiales que constituyen el cumplimiento de lo estipulado.

Si el cumplimiento es imperfecto, habrá que distinguir según si existen o no actos del acreedor -expresos o tácitos- que permitan presumir la integridad del pago, y coloquen sobre el acreedor la prueba directa de la infracción contractual. Esto se relaciona con la forma en que se puede manifestar la defectuosidad. Existirán defectos a las propiedades de la prestación que se apreciarán al momento de la perfección del contrato (search properties) -y que le permitirán al acreedor rehusar la prestación- y otras que lo harán con el uso, después del acto constitutivo (experience properties) ${ }^{31}$. Respecto de estas últimas, la prueba se encaminará a demostrar que a pesar de que el defecto se reveló después de que el acreedor se manifestó inicialmente conforme con la prestación, este resulta contemporáneo a la celebración del contrato. Con todo, para que se produzca la inversión probatoria, el deudor deberá demostrar que existió una manifestación previa de conformidad expresa o tácita por parte del acreedor. Pero si dicha manifestación no se ha producido o si desde un comienzo la prestación imperfecta fue objeto de rechazo, la prueba íntegra del cumplimiento recaerá íntegramente en el deudor, sin que el

${ }^{28}$ En este sentido PeÑallillo, D., Obligaciones. Teoría general y clasificaciones. La resolución por incumplimiento, Edit. Jurídica de Chile, Santiago, 2003, pp. 227-230, y Pizarro, C., "La culpa como elemento constitutivo del incumplimiento en las obligaciones de medio o de diligencia”, en Pizarro, C. y Vidal, Á., Incumplimiento contractual, resolución e indemnización de daños, Edit. Universidad del Rosario, Bogotá, 2010, pp. 399-405.

${ }^{29}$ En este sentido, véanse “Quiero Ponce con Sociedad de Turismo Concepción S.A.”, Corte Suprema, 26 de septiembre de 2012, Rol 1127-2012, y "Vidal Heuisler con Hospital Clínico”, Corte Suprema, 19 de enero de 2015, Rol 7215-2014, que, respectivamente, discurren sobre la carga de la prueba del incumplimiento de obligaciones de dar y hacer.

${ }^{30}$ Morales Moreno, A.M., "Problemas que plantea la unificación del concepto de incumplimiento de contrato”, en Barros, E., García, M.P. y Morales Moreno, A.M., Derecho de daños, Fundación Coloquio Jurídico Europeo, Madrid, 2009, pp. 218-219. Confróntese BARros, E., "Criterios de atribución de riesgos en materia contractual en contrapunto con la responsabilidad extracontractual”, en BArros, E., GARCíA, M.P. y Morales Moreno, A.M., Derecho de daños, Fundación Coloquio Jurídico Europeo, Madrid, 2009, pp. 188-189.

31 Tomamos estos conceptos de Martínez, L.M., La falta de conformidad en la compraventa de bienes, Bosch, Barcelona, 2007, p. 41. 
acreedor deba antes demostrar lo contrario ${ }^{32}$. En síntesis, mientras existan actos que hagan presumir la integridad del pago, más exigente será la prueba que deberá ofrecer el acreedor, y viceversa.

Si la obligación incumplida es negativa, la prueba de la contravención corresponderá al acreedor, sin perjuicio de que, en algunas ocasiones, el deudor deberá probar también el cumplimiento de las obligaciones positivas que se encuentren conectadas con aquella ${ }^{33}$. En fin, tratándose de un supuesto de incumplimiento anticipado, el acreedor también deberá demostrar los hechos objetivos que lo configuran ${ }^{34}$.

El distingo entre obligaciones de medios y de resultado no altera las cargas probatorias de los contratantes, constituyendo un mecanismo auxiliar para la determinación del objeto de la relación obligatoria ${ }^{35}$. En efecto, por regla general, probada la obligación, sea de medios o resultado, y alegado su incumplimiento por el acreedor, corresponderá al deudor acreditar el cumplimiento. Cuestión distinta es que ante un cumplimiento defectuoso el acreedor deba probar el defecto, cuando un acto suyo -por ejemplo, la ya señalada conformidad inicial- permita presumir la regularidad del cumplimiento para los fines previstos en el acto constitutivo de la obligación. Tampoco influirá la acción ejercida por el acreedor para el restablecimiento de su interés, sin perjuicio, reiteramos, de la prueba de aquellos presupuestos específicos de cada una, como ocurre con la acreditación del daño, la causalidad y la previsibilidad en la indemnización ${ }^{36-37}$.

\section{LA GARANTÍA LEGAL Y LA CARGA DE LA PRUEBA DEL INCUMPLIMIENTO}

Tomándonos de las reflexiones precedentes, podemos afirmar que al igual que el CC, la LPC diseña dos niveles de responsabilidad, tanto para productos como para servicios.

32 Por todos, Álvarez, R., La resolución de los contratos bilaterales por incumplimiento, Edit. Comares, Granada, 2009, pp. 181-182.

${ }^{33}$ En este sentido, Mosco, L., La resolución de los contratos por incumplimiento, (trad.) Pintó Ruiz, J., Dux, Ediciones y Publicaciones, Barcelona, sin fecha, pp. 122-123, pone el ejemplo de la obligación de conservación de la sustancia de la cosa arrendada (obligación negativa), que, a su vez, supone en el arrendatario la obligación de atender a aquellos trabajos de manutención y reparación que estén a su cargo por ley o por contrato.

${ }^{34} \mathrm{El}$ supuesto de hecho del incumplimiento por anticipación se produce, siguiendo a Treitel, G.H., The law of contract, Stevens \& Sons, London, 1983, p. 642, cuando "one of the parties to a contract may, before the time fixed for performance, say that he will not perform, or incapacitate himself from performing".

35 Peñallillo, D., op. cit., N ${ }^{\circ}$ 28, pp. 228-229. Sosteniendo la irrelevancia de la clasificación, pero con imposición del peso de la prueba del incumplimiento en el acreedor, véase JorDano, F., "Obligaciones de medios y de resultado (a propósito de alguna jurisprudencia reciente)”, en Anuario de Derecho Civil, $\mathrm{N}^{\circ} 1$, 1991, pp. 78-79.

${ }^{36}$ En este sentido, SACCO, R., "La resolución por incumplimiento", en LEóN, L. (selección, traducción y notas), Estudios sobre el contrato en general, Ara Editores, Lima, 2004, pp. 947-948. Confróntese, Roppo, V., El contrato, (trad.) Ariano, E., Gaceta Jurídica, Lima, 2009, p. 875, quien sostiene que el requisito de la gravedad del incumplimiento justifica, al menos respecto del remedio resolutorio, que el acreedor cargue con el peso de la prueba de la inejecución.

\footnotetext{
37 Véase supra nota 19.
} 
a. El primero se construye a partir de aquellas formas de reparación típicas que se ofrecen como alternativas a elección del mismo consumidor afectado ${ }^{38}$. En este sentido podemos mencionar: a) la reparación gratuita del bien, b) la reposición del bien y c) la devolución de la cantidad pagada (art. 20), tratándose de productos; y a) la prestación del servicio sin costo para el consumidor y b) la devolución de lo pagado por este al proveedor, en los servicios (art. 41). Todas estas parecen responder a la tipología clásica de remedios contenida en el art. 1489 CC $^{39}$. Así, la devolución de la cantidad pagada será en verdad una forma de resolución, mientras que la reparación gratuita, la reposición y la nueva prestación del servicio constituirán formas de cumplimiento forzado. Por ello, la doctrina no ha dudado en calificar como objetiva la responsabilidad que dimana del ejercicio de estas acciones ${ }^{40}$. Se trata de acciones de ejercicio extrajudicial ${ }^{41}$, que se articulan en torno al concepto unitario de incumplimiento. Hacen excepción a lo anterior las faltas de conformidad cuantitativas, reguladas en el art. $19^{42}$.

En lo que respecta a la carga de la prueba, la doctrina parece dividida. Por ejemplo, el profesor Corral pareciera ser de la idea de que el consumidor afectado debe probar el incumplimiento ${ }^{43}$. Por su parte, Rodríguez Pinto, refiriéndose a la garantía legal de servicios, sostiene que la prueba del defecto consiste en la acreditación de las condiciones de acuerdo con las que el servicio fue contratado y en la prueba de no haberse prestado este o de haberse cumplido defectuosamente. Como estos últimos son hechos negativos, se "desplaza la carga de la prueba al deudor. Es este quien deberá probar haber hecho la prestación o haberla hecho debidamente" ${ }^{4}$. A su turno, Fuentes, a quien podríamos situar en una postura intermedia, afirma que, al igual que en el CC, la distribución probatoria opera equilibradamente, siendo de carga del acreedor/consumidor los hechos

${ }^{38}$ Corral, H., Responsabilidad por productos defectuosos. Análisis y propuestas para el derecho civil y de consumo en Chile, Edit. LegalPublishing, Santiago, 2011, p. 117.

${ }^{39}$ Véase Corral, H., op. cit., N³8, p. 117; PeÑallillo, D., op. cit., No 28, pp. 430-431, y RodríGuez, P., Derecho del consumidor. Estudio crítico, Edit. LegalPublishing, Santiago, 2015, p. 49.

${ }^{40}$ En este sentido, Aimone, E., op. cit., N 10, p. 94; Corral, H., "Ley de protección al consumidor y responsabilidad civil por productos y servicios defectuosos", en Corral, H. (editor), Derecho del consumo y protección al consumidor, Cuadernos de Extensión Jurídica № 3, Universidad de los Andes, Santiago, 1999, pp. 178-181; RodríGuez, M.S., "Prestación de servicios y responsabilidad civil en la Ley sobre Protección de los Derechos de los Consumidores", en Baraona, J. y Lagos, O. (editores), La protección de los derechos de los consumidores en Chile, Cuadernos de Extensión Jurídica N ${ }^{\circ}$ 12, Universidad de los Andes, Santiago, 2006,

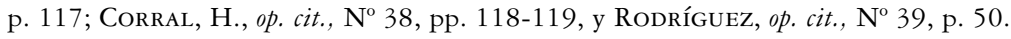

41 Contardo, J.I., “Comentario al artículo 41”, en De la Maza, I., y Pizarro, C. (directores) y Barrientos, F. (coordinadora), La protección de los derechos de los consumidores, Edit. LegalPublishing, Santiago, 2013 , p. 883 .

42 Barrientos, F., La garantía legal, Edit. LegalPublishing, Santiago, 2016, p. 169.

${ }^{43}$ Corral, H., op. cit., $\mathrm{N}^{\circ} 38$, p. 119. Cabe precisar, en todo caso, que este planteamiento lo efectúa exclusivamente en relación con la indemnización de perjuicios aneja a las formas de reparación típica que hemos señalado.

${ }^{44}$ Rodríguez, M.S., op. cit., No 40, p. 118. Idea que reitera en RodríguEz, M.S., "La responsabilidad civil del proveedor en los contratos de prestación de servicios”, en GuZMÁN, A. (editor científico), Colección de estudios de derecho civil en homenaje a la profesora Inés Pardo de Carvallo, Ediciones Universitarias de Valparaíso, Valparaíso, 2008, p. 480. 
fundantes de su pretensión y del deudor/proveedor que el contrato se encuentra extinto o cumplido ${ }^{45}$.

Por nuestra parte, estimamos que ante el vacío normativo de la LPC, no existen razones para alejarnos de las reglas del CC, interpretadas del modo expuesto en el capítulo precedente. Esto vale tanto para productos como para servicios. De esta forma, el consumidor deberá probar el contrato de consumo - con "la documentación respectiva, salvo en casos en que el proveedor tribute bajo el régimen de renta presunta, en los cuales el acto o contrato podrá ser acreditado mediante todos los medios de prueba que sean conducentes", según reza el art. 21 inc. final ${ }^{46-47}$ - y alegar el incumplimiento de lo pactado -falta de conformidad-, trasladando el peso de la prueba del cumplimiento -verificación de las condiciones estipuladas u ofrecidas-al proveedor. A este, además, le estará permitido probar, al menos tratándose de productos, que el defecto se debe a un hecho imputable al consumidor (art. 21 inc. $\left.1^{\circ}\right)^{48}$ o que no ha podido cumplir impedido

${ }^{45}$ Fuentes, op. cit., $\mathrm{N}^{\mathrm{o}} 7$, pp. 323-325.

${ }^{46}$ Lo mismo resulta aplicable en materia de servicios, conforme con lo previsto en el art. 41 inc. final.

47 Véase al respecto HüBner, A.M., "Derecho de la contratación en la ley de protección al consumidor", en Corral, H. (editor), Derecho del consumo y protección al consumidor, Cuadernos de Extensión Jurídica $\mathrm{N}^{\circ} 3$, Universidad de los Andes, Santiago, 1999, pp. 142-143.

${ }^{48}$ En cuanto a la culpa de la víctima como eximente de responsabilidad, los tribunales se muestran a veces reacios a condenar al proveedor, cuando no les asiste el convencimiento acerca de la materialidad del incumplimiento. Por ejemplo, en "Díaz Pajarito con Automotora Comercial Costabal y Echeñique S.A.", Corte de Apelaciones de Santiago, 4 de agosto de 2016, Rol 356-2016, el consumidor alegó que el vehículo que adquirió al proveedor presentaba constantes defectos, pese a haberlo ingresado al servicio técnico en más de una ocasión. El proveedor esgrimió que el hecho del consumidor provocó el desperfecto. La Corte acogió la defensa de la empresa, en los siguientes términos: "Cuarto: Que es de público conocimiento que los vehículos que funcionan con combustible de petróleo diésel tiene características especiales en cuanto a su mantenimiento que obligan a mantener la limpieza permanente del filtro de partículas diésel o FPD, limpieza que puede ser automática o forzada, esto último en el caso de que dicho filtro se encuentre obstruido por falta de dicha mantención. En esta última situación se enciende una luz de advertencia de la avería. Esta limpieza se produce automáticamente cuanto el vehículo es conducido a una determinada velocidad, lo que produce la eliminación de las partículas que van obstruyendo el filtro, así lo indica además el peritaje evacuado en autos. Esta especial condición del modelo de vehículo adquirido por la denunciante le fue informada por el proveedor como consta de la declaración que la señora Díaz Pajarito firmó, la que se encuentra agregada a los autos. Octavo: Que la prueba rendida en autos, incluyendo la pericia decretada como medida para mejor resolver, no logran formar convicción de que los desperfectos por los cuales el vehículo de la denunciante ingresó al taller de la denunciada fueron originados por defectos de fabricación del mismo, por una mala reparación en el taller de la concesionaria o por una inadecuada conducción del vehículo que derivó en la obstrucción del filtro de partículas diésel. En efecto, dicha obstrucción puede evitarse con determinadas formas de conducción en cuanto a tiempo y velocidad; en el presente caso, el vehículo debió ingresar para regenerar dicho filtro, lo que indica que este se encontraba obstruido por no haberse accionado la limpieza automática en la forma que indica el manual del usuario, proceso que correspondía exclusivamente a la conductora. La falta de certeza en cuanto al origen o causa de la obstrucción del filtro FPD impide determinar si todos los otros desperfectos derivaron de la falta de una debida mantención del señalado filtro, pues se trata de componentes mecánicos relacionados con el buen funcionamiento del FPD, especialmente, en lo relativo a la fuerza o potencia del motor".

Una doctrina similar puede verse en "Pérez de Arce Irribarra con Cencosud Retal S.A.", Corte de Apelaciones de Concepción, 17 de octubre de 2016, Rol 234-2016. La consumidora probó que sufrió una caída al interior del establecimiento demandado, como consecuencia, según alegó, del desparramamiento 
por un caso fortuito. Sin embargo, en este último caso el cumplimiento de la obligación solo se suspenderá, a menos que el suceso externo, imprevisto e irresistible se incorpore como supuesto de hecho de una imposibilidad sobrevenida absoluta de la prestación ${ }^{49}$. En apoyo de esta tesitura se encuentran las disposiciones de las letras a), c) y d) del art. 20 en materia de productos, las que envuelven obligaciones que comprometen un resultado específico, cuya verificación debe demostrar el proveedor ${ }^{50}$. Excepcionalmente, en el caso de las letras b), f) y g) -que podríamos agrupar dentro de la categoría de vicios ocultos $^{51-52}-$, la prueba será del consumidor, en la medida en que exista un acto suyo,

de un líquido en uno de sus pasillos. Al respecto, la Corte de Concepción dijo: "Tercero: Que con la prueba rendida en estos antecedentes, documental, confesional, exhibición de documentos, valorada según las reglas de la sana crítica, si bien se pudo probar que la denunciante sufrió una caída y fractura en el tobillo izquierdo, como se señala en el parte de fojas 1 -según denuncia presentada por la hija de la afectada-, en el interior del Supermercado Santa Isabel de Concepción, ubicado en calle Freire entre Rengo y Lincoyán, cuando bajaba por la escalera mecánica con barandas a ambos lados, hacia el sector de los estacionamientos, circunstancia que no fue controvertida por la denunciada; sin embargo, lo cierto es que no se logró acreditar que dicha lesión hubiere sido provocada por infracción cometida por dicha parte, al no existir antecedentes de la sustancia vertida en el piso que la habría hecho caer perdiendo el equilibrio, ni la efectividad de esto último. Cuarto: Que de acuerdo a la denuncia, y los antecedentes allegados por las partes, el centro de la controversia se refiere solamente a si la caída de la denunciada se debió al no cumplimiento de medidas de seguridad de la misma en el contexto de la existencia de un líquido en el piso que la habría hecho resbalar o perder el equilibrio a la denunciante, provocándole la lesión, lo que, como se dijo, no logró acreditarse con la prueba rendida, por lo que no existe infracción por parte de la denunciada a la Ley $\mathrm{N}^{\circ} 19.496$ en sus artículos 3 y 23 , debiendo absolverse a la denunciada”.

${ }^{49}$ En este sentido, Castilla, M., La imposibilidad de cumplir los contratos, Dykinson, Madrid, 2000, pp. $45-61$.

${ }^{50}$ En el supuesto de la letra a), por ejemplo, ("Cuando los productos sujetos a normas de seguridad o calidad de cumplimiento obligatorio no cumplan las especificaciones correspondientes”), el consumidor deberá probar la obligación y alegar que el proveedor no ha dado cumplimiento a la normativa sectorial respectiva. Este, por su parte, deberá acreditar que ha cumplido, demostrando que los productos cuentan efectivamente con las especificaciones señaladas.

En el caso de la letra c) ("Cuando cualquier producto, por deficiencias de fabricación, elaboración, materiales, partes, piezas, elementos, sustancias, ingredientes, estructura, calidad o condiciones sanitarias, en su caso, no sea enteramente apto para el uso o consumo al que está destinado o al que el proveedor hubiese señalado en su publicidad") el consumidor soportará la carga de probar el contrato y alegar que el producto resulta inidóneo para la finalidad expresamente prevista. El proveedor, en tanto, deberá demostrar la idoneidad del bien.

Sin embargo, tratándose de la letra d) ("Cuando el proveedor y consumidor hubieren convenido que los productos objeto del contrato deban reunir determinadas especificaciones y esto no ocurra”), el consumidor deberá probar el acuerdo contractual, basado en ello el producto debe cumplir con una determinada especificación, alegar que no la cumple, trasladando el peso de la prueba del cumplimiento al proveedor.

${ }^{51}$ La letra b) señala: "Cuando los materiales, partes, piezas, elementos, sustancias o ingredientes que constituyan o integren los productos no correspondan a las especificaciones que ostenten o a las menciones del rotulado".

La letra f) dice: "Cuando la cosa objeto del contrato tenga defectos o vicios ocultos que imposibiliten el uso a que habitualmente se destine".

Finalmente, la letra g) dispone: "Cuando la ley de los metales en los artículos de orfebrería, joyería y otros sea inferior a la que en ellos se indique".

52 En todo caso, es posible precisar, como lo hace IsLER, E., El producto defectuoso en la Ley $N^{o} 19.496$, Edit. Librotecnia, Santiago, 2013, pp. 169-175, que la categoría de vicios ocultos que amadriga la Ley $\mathrm{N}^{\circ} 19.496$ se aleja del concepto de vicios redhibitorios contenido en el CC. 
como una manifestación inicial de conformidad demostrada por el deudor, que permita presumir la integridad del pago en favor de este último. En caso contrario, esto es, que no exista dicha manifestación de conformidad o si el consumidor ha rehusado desde un comienzo la prestación imperfecta, no será necesario que pruebe la defectuosidad. Finalmente, en el supuesto de la letra e $)^{53}$, el consumidor deberá probar la existencia de una garantía convencional ofrecida por el proveedor y alegar que, a pesar de haber agotado las posibilidades que ofrece, las deficiencias subsisten.

Lo mismo se puede sostener en relación con los servicios, ya que en ellos también puede hablarse de un resultado cuya realización garantiza el proveedor ${ }^{54-55}$.

Es factible hacer presente además que la LPC dispone que tratándose de bienes amparados por una garantía convencional, "el consumidor, antes de ejercer alguno de los derechos que le confiere el artículo 20, deberá hacerla efectiva ante quien corresponda y agotar las posibilidades que ofrece, conforme a los términos de la póliza" (art. 21 inc. $9^{\circ}$ ). Esta disposición ha sido severamente criticada por la doctrina ${ }^{56}$, ya que, en principio, su tenor literal obligaría al consumidor a ejercer los remedios que ofrece la garantía voluntaria dispuesta por el proveedor, en desmedro de la vía judicial directa. Pero incluso reconociendo una mayor persuasión en los argumentos que apoyan la opción del consumidor por la vía que mejor estime para el resguardo de su interés ${ }^{57}$, surge el problema práctico de determinar el objeto y las cargas probatorias en uno y otro caso, esto es, en los supuestos en que el consumidor opte por dirigirse primeramente ante el proveedor -y luego ante el juez-o accione directamente en sede judicial.

53 Letra e): "Cuando después de la primera vez de haberse hecho efectiva la garantía y prestado el servicio técnico correspondiente, subsistieren las deficiencias que hagan al bien inapto para el uso o consumo a que se refiere la letra c). Este derecho subsistirá para el evento de presentarse una deficiencia distinta a la que fue objeto del servicio técnico, o volviere a presentarse la misma, dentro de los plazos a que se refiere el artículo siguiente".

${ }^{54}$ Rodríguez, M.S., op. cit., N 44, p. 480.

55 En este sentido, en "González Ramírez con Constructora y Administradora Uno S.A.", Corte de Apelaciones de Santiago, 28 de septiembre de 2016, Rol 1007-2016, el consumidor probó haber estacionado su vehículo en las dependencias del proveedor, el que fue sustraído a pesar de que este último alegó haber dado cumplimiento a la obligación de seguridad que le asistía. El tribunal resolvió: "Que se encuentra también acreditado que el 6 de septiembre de 2013, la empresa demandada ninguna respuesta entregó al consumidor afectado, limitándose a afirmar en el libelo pretensor, que revisada las cámaras de seguridad su parte no es responsable de los hechos. Sin embargo, no allegó a la causa las señaladas cámaras, ni algún informe en relación a su contenido. En el caso de autos, acreditado los hechos de la acción resarcitoria corresponde a la demandada probar la diligencia en relación a las medidas de seguridad del lugar el día de los hechos, resultando insuficiente para ese fin la prueba documental acompañada por la demandada, pues con ella no es posible inferir, las concretas medidas de seguridad adoptadas en la fecha señalada y en la hora en que el demandante afirma fue sustraído su vehículo".

${ }^{56}$ Por todos, Corral, H., "Relaciones entre la 'garantía legal' y la garantía voluntaria del proveedor en la Ley de Protección de los Derechos del Consumidor”, en Elorriaga, F. (coord.), Estudios de Derecho Civil VII, Edit. LegalPublishing, Santiago, 2012, pp. 409 y s., y BARrientos, op. cit., No 42, pp. $246-252$.

${ }^{57}$ Ver supra nota precedente. 
Todo parece indicar que, en el primer caso, el objeto de la prueba del litigio se referirá al cumplimiento, por parte del proveedor, de las formas de reparación típicas dispuestas en favor del consumidor, de modo que a este le corresponderá dar la prueba de la existencia de la garantía convencional y alegar que, habiendo optado por ella, subsisten las deficiencias. A su turno, al proveedor tocará probar que dio cumplimiento a los términos de la garantía ofrecida, solucionando definitivamente los defectos, o que no pudo hacerlo por un hecho imputable al consumidor o por encontrase impedido por una circunstancia extraña a su esfera de control (caso fortuito). En cambio, si el consumidor opta en forma directa por el recurso judicial, el objeto de la prueba se encaminará derechamente a la demostración de la falta de conformidad alegada ${ }^{58-59}$.

${ }^{58}$ En "Varas Escobar con Comercial Automotora Prime Ltda.", Corte de Apelaciones de Antofagasta, 24 de febrero de 2010, Rol 150-2009, el consumidor adquirió un vehículo nuevo, el que, a la semana de uso, comenzó a presentar fallas que obligaron a ingresarlo al taller del proveedor al menos en tres ocasiones. Este, al contestar la denuncia y demanda civil interpuesta por el consumidor, sostuvo que al no haberse efectuado un reclamo respecto de la venta, la discusión debía circunscribirse a la forma cómo se prestó el servicio técnico (postventa), en cuyo contexto no habría incurrido en contravención alguna, por cuanto atendió gratuitamente al consumidor en todas las oportunidades en que fue requerido. La Corte, sin embargo, desechó esta alegación, y, para los efectos que nos interesa, destaca que resultó probado en el juicio que el proveedor no cumplió con la garantía, al mantenerse los desperfectos, a pesar de los constantes ingresos a taller. Así se lee del considerando undécimo del fallo: "Que la adquisición de un vehículo nuevo y sin uso, cualquiera sea el precio, exige un funcionamiento impecable desde todo punto de vista, de manera que el proveedor tenía la obligación de saber los pormenores al respecto antes de entregarlo al comprador y al no obrar de ese modo actuó con negligencia en la venta del bien y en las deficiencias posteriores que presentaba aún después de haber estado en el taller, existiendo por tanto una deficiencia en la prestación del servicio técnico de reparación del automóvil. Por consiguiente ha resultado probada la infracción a la Ley de Protección al Consumidor atribuida a la querellada".

Por su parte, en "Cruz Mamani con Administradora de Supermercados Hiper Limitada", Corte de Apelaciones de Arica, 23 de septiembre de 2016, Rol 48-2016, el demandante alegó que el notebook que adquirió al proveedor presentaba problemas de conexión a Wifi, los que no se solucionaron a pesar de que el consumidor llevó el equipo al servicio técnico. El proveedor, por su parte, alegó que la devolución del dinero solo era procedente cuando el servicio técnico podía revisar en dos oportunidades el producto. La Corte de Arica, confirmando lo resuelto en sede de policía local, entendió consumada la infracción al no haber probado el proveedor que la reparación produjo el resultado de subsanar los defectos en la única ocasión en la que el producto debía ser derivado al servicio técnico. Así se colige del considerando séptimo: "Que, del análisis de la prueba señalada se concluye que se está en presencia de una infracción a lo preceptuado en el artículo 23 de la Ley $\mathrm{N}^{\circ}$ 19.496, el cual establece que 'Comete infracción a las disposiciones de la presente ley el proveedor que, en la venta de un bien o en la prestación de un servicio, actuando con negligencia, causa menoscabo al consumidor debido a fallas o deficiencias en la calidad, cantidad, identidad, sustancia, procedencia, seguridad, peso o medida del respectivo bien o servicio', por cuanto se ha logrado acreditar que el equipo computacional adquirido poseía problemas con su tarjeta inalámbrica, lo que impedía su correcta conexión a alguna red wifi, problema que se mantuvo incluso cuando este fue reparado por el servicio técnico. Agrava lo anterior el hecho que la denunciada exija una segunda revisión del equipo, por el mismo servicio técnico, para proceder a la devolución del dinero, situación que implica crear una exigencia que no se encuentra establecida en el artículo 20 del cuerpo legal citado”.

${ }^{59}$ Lo mismo se puede sostener respecto de la garantía de servicios, si entendemos que la reclamación de que trata el art. 41 admite también una fase prejudicial ante el mismo proveedor. 
b. Finalmente, el segundo nivel de responsabilidad se circunscribe a la acción de perjuicios que la LPC permite deducir sin perjuicio de las formas de reparación típicas que conforman la garantía legal (arts. 20 inc. $1^{\circ}$ y 41 inc. $2^{\circ}$ ). El profesor Corral, según adelantamos $^{60}$, entiende que ante el vacío legislativo de la LPC debe aplicarse el art. 1547 inc. $3^{\circ} \mathrm{CC}$, con lo que "podría concluirse que el demandante debe probar el incumplimiento y será de cargo del demandado demostrar que actuó con la diligencia debida (...), es decir, se trataría de un caso de responsabilidad con culpa presunta" ${ }^{61}$. Por nuestra parte, sostenemos que el juicio de imputación se fundará en el incumplimiento material ya determinado en la fase material o primer nivel de responsabilidad, de modo que el objeto y la carga de la prueba se orientarán a establecer la existencia de daños, si estos se vinculan causalmente con la inejecución y, finalmente, si la extensión de los perjuicios cuadra con la distribución de riesgos contenida en el contrato de consumo ${ }^{62-63}$. Todos estos extremos deberán ser demostrados fehacientemente por el consumidor ${ }^{64}$. En cuanto a la previsibilidad, más allá de la discusión acerca de su virtualidad como presupuesto de la indemnización en sede de contrato de consumo ${ }^{65}$, lo cierto es que la LPC favorece la posición de la parte insatisfecha, al sancionar con nulidad, en el art. 16 c), las cláusulas del contrato que "pongan de cargo del consumidor los efectos de deficiencias, omisiones o errores administrativos, cuando ellos no le sean imputables”. De este modo, todo parece indicar que esta disposición distribuye en forma imperativa los riesgos en

\footnotetext{
${ }^{60}$ Véase supra nota 43.

${ }^{61}$ Corral, H., op. cit., N ${ }^{\circ} 38$, p. 119. En términos similares, aunque no categóricos, véase Barrientos, op. cit., $\mathrm{N}^{\circ} 42$, pp. 130-132.

${ }^{62}$ Por supuesto, nada impide que el consumidor deduzca una acción de perjuicios autónoma a los remedios de la garantía legal, teniendo presente lo dispuesto en los arts. 20 y 41 . En dicho caso, sin embargo, el régimen de la carga de la prueba del incumplimiento será el mismo que hemos planteado.

63 Véase supra nota 19.

${ }^{64}$ Por ejemplo, en "Kurth Rojas con Country Club Prince of Wales”, Corte de Apelaciones de Santiago, 5 de octubre de 2016, Rol 962-20016, el proveedor fue absuelto de la acción indemnizatoria deducida por el consumidor, pese a que resultó probado en el proceso que a este le fueron sustraídas una serie de especies indeterminadas desde el vehículo que estacionó en las dependencias del primero. Dijo la Corte: “2.- Que en cuanto dice relación con el daño patrimonial que alega haber sufrido el querellante y demandante civil, cabe precisar que las partes y piezas de lo obrado en la carpeta investigativa del Ministerio Púbico, en términos generales, dicen relación con los hechos reseñados por el señor Kurth Rojas y lo verificado por Carabineros, esto es, la dinámica de como estos habrían ocurrido, pero sin existir pruebas respecto de la existencia del dinero y demás especies que habrían sido robadas desde el interior de su vehículo actor, salvo lo que él expuso en las instancias respectivas. $3^{\circ}$.- Que, en lo tocante al daño moral, no hay prueba idónea para darlo por establecido ya sea respecto del actor y sus cercanos, sin perjuicio de representar que analizando el proceso se advierte que el querellante y demandante civil, en la oportunidad procesal correspondiente, tuvo la oportunidad para probar los daños a través de las pericias que solicitó en el comparendo de contestación y prueba y no llevó a la práctica".

${ }^{65}$ En este sentido, es importante anotar que de a poco se ha alzado una corriente que objeta su condición de presupuesto de la responsabilidad contractual en el ámbito del derecho del consumidor, tomando en consideración que este criterio supone que las partes hayan tenido realmente la posibilidad de meditar y discutir los términos del convenio. Al respecto, véase Picasso, S., La singularidad de la responsabilidad contractual, Abeledo Perrot, Buenos Aires, 2011, p. 235.
} 
favor del consumidor, porque, salvo que esas contingencias fueren detonadas por él u obedezcan a una causa extraña a la esfera de control, sus efectos siempre deberán ser soportados por el proveedor.

\section{REFLEXIONES CONCLUSIVAS}

1. La LPC no contiene disposiciones referidas a la carga de la prueba del incumplimiento, lo que obliga a recurrir a las disposiciones supletorias del CC.

2. De acuerdo con las reglas del CC, corresponde distinguir dos niveles de responsabilidad y regímenes probatorios relacionados con el incumplimiento contractual. En el primero, toca al acreedor probar la existencia de la obligación y alegar el incumplimiento, para poner del lado del deudor el peso de la prueba del pago o la extinción de aquella de otro modo. Este sistema se altera cuando el cumplimiento es imperfecto y existe algún acto del acreedor, acreditado por el deudor, que haga presumir la integridad del cumplimiento. Lo mismo acontece cuando la obligación es negativa o en el supuesto de incumplimiento por anticipación. El segundo nivel de responsabilidad, referido al juicio de imputación de los daños, se construirá a partir del incumplimiento objetivo determinado en la etapa material y tendrá por objeto establecer si estos deben ser soportados por el contratante deudor, cuando concurren los presupuestos de causalidad y previsibilidad. En este caso, el deudor podrá exonerarse de responsabilidad, probando una causa extraña que haya interferido el nexo causal.

3. Por regla general, la garantía legal de productos y servicios de la LPC se encuentra en el primer nivel de responsabilidad. Por ello, su naturaleza es objetiva y, en lo sustancial, se regirá por las mismas reglas probatorias del CC. La prueba se encaminará a la acreditación de la conformidad del producto o servicio según el interés del acreedor protegido por la regla contractual y las cargas probatorias serán las mismas del Código sustantivo. Hará excepción a esta regla el supuesto de ejercicio de la garantía convencional en forma previa al recurso judicial, en cuyo caso la prueba que se rinda en el proceso judicial posterior se referirá al cumplimiento exacto - por parte del proveedor- de las formas de reparación contenidas en los arts. 20 y 41, cuya carga corresponderá precisamente a este. La indemnización de perjuicios, por su parte, se encuentra en el segundo nivel de responsabilidad y su objeto será establecer que los daños que ha probado el consumidor son causalmente reconducibles al incumplimiento y que estos constituyen un riesgo que debe administrar el proveedor, de acuerdo con la regla contractual. Lo anterior se entiende sin perjuicio de la prueba liberatoria que este pueda ofrecer (hecho imputable al deudor y caso fortuito).

4. La inversión probatoria que prohíbe la LPC por ser perjudicial para el consumidor será la que coloque a su cargo la prueba del incumplimiento, en cualquiera de sus formas, salvo en aquellos supuestos en que, conforme con el CC, le corresponda probar la inejecución de lo pactado. 


\section{BIBLIOGRAFÍA}

Aimone, E., Derecho de protección al consumidor, Edit. Jurídica Conosur, Santiago, 1998.

Alessandri, A., Teoría general de las obligaciones, Edit. Jurídica Ediar Conosur, Santiago, 1988.

Álvarez, R., La resolución de los contratos bilaterales por incumplimiento, Edit. Comares, Granada, 2009.

BARAONA, J., "Responsabilidad contractual y factores de imputación de daños: apuntes para una relectura en clave objetiva", en Revista Chilena de Derecho, v. 24, Nº 1, 1997.

Baraona, J., "La regulación contenida en la Ley No 19.496 sobre Protección de los Derechos de los Consumidores y las reglas del Código Civil y Comercial sobre contratos: un marco comparativo", en Revista Chilena de Derecho, v. 41, No 2, 2014.

Barrientos, F., La garantía legal, Edit. LegalPublishing, Santiago, 2016.

BARros, E., "La diferencia entre estar obligado y ser responsable en el derecho de los contratos". En Corral, H. y Rodríguez, M.S. (coord.), Estudios de Derecho Civil II, Edit. LexisNexis, Santiago, 2007.

BARros, E., "Criterios de atribución de riesgos en materia contractual en contrapunto con la responsabilidad extracontractual”, en Barros, E., García, M.P. y Morales Moreno, A.M., Derecho de daños, Fundación Coloquio Jurídico Europeo, Madrid, 2009.

Castilla, M., La imposibilidad de cumplir los contratos, Dykinson, Madrid, 2000.

Claro Solar, L., Explicaciones de derecho civil chileno y comparado. De las obligaciones, t. XI, Edit. Nascimento, Santiago, 1937.

Contardo, J.I., "Comentario al artículo 41", en De la Maza, I., y Pizarro, C. (directores) y Barrientos, F. (coordinadora), La protección de los derechos de los consumidores, Edit. LegalPublishing, Santiago, 2013.

Contardo, J.I., Indemnización y resolución por incumplimiento, Edit. Thomson Reuters, Santiago, 2015.

Corral, H., "Ley de protección al consumidor y responsabilidad civil por productos y servicios defectuosos", en Corral, H. (editor), Derecho del consumo y protección al consumidor, Cuadernos de Extensión Jurídica No 3, Universidad de los Andes, Santiago, 1999.

Corral, H., Contratos y daños por incumplimiento, Edit. LegalPublishing, Santiago, 2010.

Corral, H., Responsabilidad por productos defectuosos. Análisis y propuestas para el derecho civil y de consumo en Chile, Edit. LegalPublishing, Santiago, 2011.

Corral, H., "Sobre la carga de la prueba en el proyecto de Código Procesal Civil”, en Aguirrezabal, M. (editor), Justicia Civil: perspectivas para una reforma en la legislación chilena, Cuadernos de Extensión Jurídica No 23, Universidad de los Andes, Santiago, 2012.

Corral, H., "Relaciones entre la 'garantía legal' y la garantía voluntaria del proveedor en la Ley de Protección de los Derechos del Consumidor”, en Elorriaga, F. (coord.), Estudios de Derecho Civil VII, Edit. LegalPublishing, Santiago, 2012.

Cortez, G., El nuevo procedimiento regulado en la Ley $N^{o} 19.496$ sobre Protección de los Derechos de los Consumidores, Edit. LexisNexis, Santiago, 2004.

Fuentes, C., "Comentario al artículo 16 D)", en De la Maza, I., y Pizarro, C. (directores) y Barrientos, F. (coordinadora), La protección de los derechos de los consumidores, Edit. LegalPublishing, Santiago, 2013.

García, M., Cláusulas limitativas de la responsabilidad contractual, Edit. Tecnos, Madrid, 1965.

Guerrero, J.L., "La distinción entre contravención infraccional e incumplimiento contractual o contravención civil en materia de protección de derechos del consumidor”, en Guzmán, A. (editor científico), Colección de estudios de derecho civil en homenaje a la profesora Inés Pardo de Carvallo, Ediciones Universitarias de Valparaíso, Valparaíso, 2008. 
HÜBNER, A.M., "Derecho de la contratación en la ley de protección al consumidor", en Corral, H. (editor), Derecho del consumo y protección al consumidor, Cuadernos de Extensión Jurídica $\mathrm{N}^{\circ}$ 3, Universidad de los Andes, Santiago, 1999.

IsLER, E., El producto defectuoso en la Ley No 19.496, Edit. Librotecnia, Santiago, 2013.

JoRdano, F., La responsabilidad contractual, Civitas, Madrid, 1987.

Jordano, F., "Obligaciones de medios y de resultado (a propósito de alguna jurisprudencia reciente)", en Anuario de Derecho Civil, No 1, 1991.

Lorenzini, J., "La carga dinámica de la prueba en materias de consumo: un desafío pendiente para asegurar la igualdad procesal del consumidor y proveedor", en Tapia, M., Gatica, M.P. y Verdugo, J. (coordinadores), Estudios de derecho civil en homenaje a Gonzalo Figueroa Yáñez, Edit. LegalPublishing, Santiago, 2014.

Martínez, L.M., La falta de conformidad en la compraventa de bienes, Bosch, Barcelona, 2007.

Morales Moreno, A.M., "Comentario al artículo 35”, en Díez-Picazo, L. (coord.), La compraventa internacional de mercaderías. Comentario de la Convención de Viena, Thomson Civitas, Cizur Menor, 2006.

Morales Moreno, A.M., "Problemas que plantea la unificación del concepto de incumplimiento de contrato”, en Barros, E., García, M.P. y Morales Moreno, A.M., Derecho de daños, Fundación Coloquio Jurídico Europeo, Madrid, 2009.

Morales Moreno, A.M., "Claves de la modernización del derecho de contratos", en De la Maza, I., Morales Moreno, A.M. y Vidal, A., Estudios de derecho de contratos. Formación, cumplimiento e incumplimiento, Edit. Thomson Reuters, Santiago, 2014.

Mosco, L., La resolución de los contratos por incumplimiento, (trad.) Pintó Ruiz, J., Dux, Ediciones y Publicaciones, Barcelona, sin fecha.

Oviedo, J., La garantía por vicios ocultos en la compraventa, Edit. Temis, Bogotá, 2015.

Peñailillo, D., Obligaciones. Teoría general y clasificaciones. La resolución por incumplimiento, Edit. Jurídica de Chile, Santiago, 2003.

PeÑailillo, D., "Responsabilidad contractual objetiva”, en Pizarro, C. (coord.), Estudios de Derecho Civil IV, Edit. LegalPublishing, Santiago, 2009.

PiCAsso, S., La singularidad de la responsabilidad contractual, Abeledo Perrot, Buenos Aires, 2011.

Pizarro, C., "La culpa como elemento constitutivo del incumplimiento en las obligaciones de medio o de diligencia", en Pizarro, C. y Vidal, Á., Incumplimiento contractual, resolución e indemnización de daños, Edit. Universidad del Rosario, Bogotá, 2010.

Rodríguez, P., Derecho del consumidor. Estudio crítico, Edit. LegalPublishing, Santiago, 2015.

Rodríguez, M.S., "Prestación de servicios y responsabilidad civil en la Ley sobre Protección de los Derechos de los Consumidores", en Baraona, J. y Lagos, O. (editores), La protección de los derechos de los consumidores en Chile, Cuadernos de Extensión Jurídica No 12, Universidad de los Andes, Santiago, 2006.

Rodríguez, M.S., "La responsabilidad civil del proveedor en los contratos de prestación de servicios", en Guzmán, A. (editor científico), Colección de estudios de derecho civil en homenaje a la profesora Inés Pardo de Carvallo, Ediciones Universitarias de Valparaíso, Valparaíso, 2008.

Roppo, V., El contrato, (trad.) Ariano, E., Gaceta Jurídica, Lima, 2009.

Rosenberg, L., La carga de la prueba, (trad.) Krotoschin, E., B de F, Buenos Aires, 2002.

SACCO, R., "La resolución por incumplimiento", en León, L. (selección, traducción y notas), Estudios sobre el contrato en general, Ara Editores, Lima, 2004.

Sandoval, R., Derecho del consumidor. Protección del consumidor en la Ley $N^{\circ}$ 19.496, de 1997, modificada por la Ley $N^{\circ}$ 19.955, de 14 de julio de 2004, y en la legislación comparada, Edit. Jurídica de Chile, Santiago, 2004. 
TAPIA, M. y Valdivia, J.M., Contrato por adhesión. Ley No 19.496, Edit. Jurídica de Chile, Santiago, 2002.

Treitel, G.H., The law of contract, Stevens \& Sons, London, 1983.

VIDAL, Á., "Responsabilidad civil por incumplimiento de obligaciones con objeto fungible. Una relectura de las disposiciones del Código Civil sobre incumplimiento", en De la Maza, I., Morales Moreno, A.M. y Vidal, A., Estudios de derecho de contratos. Formación, cumplimiento e incumplimiento, Edit. Thomson Reuters, Santiago, 2014.

Von Tuhr, A., Tratado de las obligaciones, (trad.) Roces, W., Edit. Comares, Granada, 2007.

\section{Sentencias citadas}

“Arias Madariaga con Sodimac S.A.", Corte de Apelaciones de Concepción, 24 de diciembre de 2007, Rol 174-2005.

"Varas Escobar con Comercial Automotora Prime Ltda.", Corte de Apelaciones de Antofagasta, 24 de febrero de 2010, Rol 150-2009.

"Quiero Ponce con Sociedad de Turismo Concepción S.A.", Corte Suprema, 26 de septiembre de 2012, Rol 1127-2012.

"Sernac con Cencosud", Corte Suprema, 24 de abril de 2013, Rol 12.355-2011.

"Vidal Heuisler con Hospital Clínico”, Corte Suprema, 19 de enero de 2015, Rol 7215-2014.

"Díaz Pajarito con Automotora Comercial Costabal y Echeñique S.A.", Corte de Apelaciones de Santiago, 4 de agosto de 2016, Rol 356-2016.

"Cruz Mamani con Administradora de Supermercados Hiper Limitada", Corte de Apelaciones de Arica, 23 de septiembre de 2016, Rol 48-2016.

"GonzÁlez Ramírez con Constructora y Administradora Uno S.A.", Corte de Apelaciones de Santiago, 28 de septiembre de 2016, Rol 1007-2016.

"Kurth Rojas con Country Club Prince of Wales", Corte de Apelaciones de Santiago, 5 de octubre de 2016, Rol 962-20016.

"PÉrez de Arce Irribarra con Cencosud Retal S.A.", Corte de Apelaciones de Concepción, 17 de octubre de 2016, Rol 234-2016. 
